\title{
BMJ Open Right Iliac Fossa Pain Treatment (RIFT) Study: protocol for an international, multicentre, prospective observational study
}

RIFT Study Group On behalf of the West Midlands Research Collaborative

To cite: RIFT Study Group 0n behalf of the West Midlands Research Collaborative. Right Iliac Fossa Pain Treatment (RIFT) Study: protocol for an international, multicentre, prospective observational study. BMJ Open 2018;8:e017574. doi:10.1136/ bmjopen-2017-017574

- Prepublication history and additional material for this paper are available online. To view, please visit the journal (http:// dx.doi.org/10.1136/bmjopen2017-017574).

Received 6 May 2017

Revised 2 July 2017

Accepted 20 July 2017

\section{CrossMark}

The West Midlands Research Collaborative, The Department of Academic Surgery, University of Birmingham, Birmingham, West Midlands, UK

Correspondence to Dmitri Nepogodiev; d.nepogodiev@bham.ac.uk

\section{ABSTRACT}

Introduction Patients presenting with right iliac fossa (RIF) pain are a common challenge for acute general surgical services. Given the range of potential pathologies, RIF pain creates diagnostic uncertainty and there is subsequent variation in investigation and management. Appendicitis is a diagnosis which must be considered in all patients with RIF pain; however, over a fifth of patients undergoing appendicectomy, in the UK, have been proven to have a histologically normal appendix (negative appendicectomy). The primary aim of this study is to determine the contemporary negative appendicectomy rate. The study's secondary aims are to determine the rate of laparoscopy for appendicitis and to validate the Appendicitis Inflammatory Response (AIR) and Alvarado prediction scores.

Methods and analysis This multicentre, international prospective observational study will include all patients referred to surgical specialists with either RIF pain or suspected appendicitis. Consecutive patients presenting within 2-week long data collection periods will be included. Centres will be invited to participate in up to four data collection periods between February and August 2017. Data will be captured using a secure online data management system. A centre survey will profile local policy and service delivery for management of RIF pain. Ethics and dissemination Research ethics are not required for this study in the UK, as determined using the National Research Ethics Service decision tool. This study will be registered as a clinical audit in participating UK centres. National leads in countries outside the UK will oversee appropriate registration and study approval, which may include completing full ethical review. The study will be disseminated by trainee-led research collaboratives and through social media. Peer-reviewed publications will be published under corporate authorship including 'RIFT Study Group' and 'West Midlands Research Collaborative'.

\section{INTRODUCTION}

Right iliac fossa (RIF) pain is one of the most common presentations to acute general surgical services. ${ }^{1}$ Causes include appendicitis, other gastrointestinal, urological, gynaecological, vascular and musculoskeletal pathologies. Given this range of potential
Strengths and limitations of this study

- This study will collect prospective, observational data on a large number of patients across Europe. A preplanned validation process will verify case ascertainment and data accuracy.

- The study uses the UK National Research Collaborative model to capture high-quality data while minimising the burden on participating centres.

- Unlike previous studies, the clinical risk scores will be validated against a prospective cohort of patients presenting with undifferentiated right iliac fossa pain rather than patients who have undergone appendicectomy.

- Within the remit of this observational study, it will not be possible to track patient readmissions to centres other than the index admitting hospital or readmission rates beyond 30 days.

- This protocol is designed to be carried out alongside routine clinical practice. This limits the quantity and complexity of data it is feasible to collect. Specific data regarding antibiotic therapy for RIF pain and presenting symptoms outside of those included within risk scores will not be collected.

pathologies, variation in presentation and similarity to other conditions, particularly ovarian pathologies in women of reproductive age, diagnosing appendicitis can be a challenge. ${ }^{2}$ Traditionally, surgeons have relied on clinical history, examination findings and basic laboratory investigations for diagnosis. Objective stratifiers such as the Appendicitis Inflammatory Response (AIR) ${ }^{3}$ and Alvarado scores ${ }^{4}$ have been developed to combat this diagnostic uncertainty; yet, these derived from small retrospective cohorts, are poorly validated, and not widely used. ${ }^{5}$

Since delayed appendicectomy is associated with increased risk of complications, prompt diagnosis and treatment is essential. ${ }^{6}$ Diagnostic uncertainty, coupled with the risks of diagnostic delay, has led to surgeons having 
a low threshold for operating on patients with equivocal symptoms resulting in high rates of negative appendicectomy: a national audit in 2012 found the UK's negative appendicectomy rate to be $20.6 \% .^{78}$

Recent guidelines stipulate that appendicectomy should be performed laparoscopically unless this is contraindicated $^{910}$ (table 1). However, in 2012 one-third of patients underwent open appendicectomy. ${ }^{7}$ Unlike laparoscopic surgery, open procedures typically commit the surgeon to proceed to appendicectomy even if the appendix is found to be macroscopically normal once visualised. ${ }^{8}$

This study will test the hypothesis that, associated with increased take-up of laparoscopy, the negative appendicectomy rate will have decreased since $2012 .{ }^{8}$ To inform the implementation of recent guidelines which mandate risk stratification of patients with RIF pain, this study will also validate the AIR and Alvarado scores in a large, prospective, international cohort. ${ }^{9} 10$

\section{METHODS AND ANALYSIS}

This prospective, observational, multicentre study will be coordinated by trainee-led research networks which have been described previously. ${ }^{11} 12$

\section{Aims and objectives}

The primary aim of this study is to determine the negative appendicectomy rate. The secondary aims of this study are to determine the rate of laparoscopy for appendicectomy and to validate the AIRS and Alvarado scores for acute appendicitis. A centre survey will profile local policy and service delivery for management of patients presenting with RIF pain.

\section{Patients and centres}

Any hospital that offers acute general surgical services will be eligible to participate. Local collaborators at each centre will prospectively collect data during 2-week long study periods, on consecutive patients referred to the general or paediatric surgery units with RIF pain or suspected appendicitis. Each centre will be able to submit data from up to four study periods between February and August 2017. Patients will be identified prospectively via hospital computer systems, handover lists and by the clinical surgical team. Patients who are pregnant have had abdominal surgery in the preceding 90 days, or have had previous appendicectomy, right hemicolectomy or total colectomy will be excluded (figure 1). Variables required to calculate the AIRS and Alvarado scores will be collected at time of presentation to the surgical unit.

\section{Follow-up}

Patients will be followed throughout their admission to determine their treatment pathway and length of stay. Data will also be collected on histology and readmission rates, for both the operated and non-operated groups, within 30 days. Collaborators will access electronic records, emergency department and theatre systems and patient notes to collect data. The group who undergo an operation will be followed up to determine the negative appendicectomy rate, and the non-operative group will be followed up to allow for the validation of the AIR and Alvarado scores low risk prediction for this group. The non-operative group will also include those patients diagnosed as simple appendicitis and treated non-operatively and will require follow-up to assess whether they then require a subsequent operation. No patient identifiable information will be collected.

\section{Centre survey}

A consultant surgeon at each participating centre will complete a short questionnaire regarding the guidelines, protocols and resources available for the investigation and management of RIF pain in their hospital (table 2).

\section{Project management and recruitment}

The RIFT steering committee (see online supplementary appendix 1) will be responsible for protocol development, data collection and data analysis. A structured system of national, regional and local leadership has been created to coordinate the RIFT study. National leads will oversee participation in RIFT within their countries through networks including the West Midlands Research Collaborative, UK National Surgical Research Collaborative and Italian Surgical Research Group, as well as through social media platforms. ${ }^{13}$ Regional leads will recruit, advise and ensure the correct approvals are in place for each hospital within their region. Local leads will oversee data collection in their hospital, ensuring adherence to local governance protocols and continuous data collection across the 2-week periods. Up to three collaborators per 2-week period, per hospital, will be recruited to participate. A secure server running the 'Research Electronic Data Capture' (REDCap, Boston, Massachusetts) web application hosted by the University of Birmingham, UK, will be used to collect and securely store data.

\section{Sample size and statistical analysis}

Based on pilot studies across four centres, we estimate that each centre will capture approximately 10 patients with RIF pain per week. The steering committee has received expressions of interest in participation from over 150 centres. It is estimated that around 75 centres will participate during each period. This would result in approximately 6000 patients being included in RIFT across the four data collection periods. It is anticipated that around 20\% (1200 patients) will undergo appendicectomy.

Data will be reported in accordance with Strengthening The Reporting of Observational studies in Epidemiology guidelines for observational studies. ${ }^{14}$ Differences between patient, disease and operative specific factors will be tested using Student's t-test for continuous data ( $\mathrm{p}$ value) and $\chi^{2}$ for categorical data (reported as $\chi^{2}, p$ value). A p-value of 0.05 will be accepted as significant.

Preplanned analyses will include and are not limited to: (1) variation in the negative appendicectomy and 
Table 1 A complete compilation and comparison of the WSES 2016 and the EAES 2016 guidance on the investigation and management of appendicitis

\begin{tabular}{|c|c|c|c|}
\hline Society & $\begin{array}{l}\text { Statement } \\
\text { number }\end{array}$ & Guidance statement & $\begin{array}{l}\text { Captured } \\
\text { within the RIFT } \\
\text { Study }\end{array}$ \\
\hline \multicolumn{4}{|c|}{ (1) Diagnostic efficiency of clinical scoring systems } \\
\hline EAES & Preop R1 & $\begin{array}{l}\text { The combined variables of clinical assessment and biochemical testing in the } \\
\text { Alvarado score should be used to determine the likelihood of appendicitis. }\end{array}$ & Yes \\
\hline WSES & 1.1 & $\begin{array}{l}\text { The Alvarado score (with cut-off score }<5 \text { ) is sufficiently sensitive to exclude acute } \\
\text { appendicitis. }\end{array}$ & Yes \\
\hline WSES & 1.2 & The Alvarado score is not sufficiently specific in diagnosing acute appendicitis. & Yes \\
\hline WSES & 1.3 & $\begin{array}{l}\text { An ideal (high sensitivity and specificity), clinically applicable, diagnostic scoring } \\
\text { system/clinical rule remains outstanding. This remains an area for future research. }\end{array}$ & Yes \\
\hline
\end{tabular}

(2) Role of imaging

\begin{tabular}{|c|c|c|c|}
\hline WSES & 2.1 & $\begin{array}{l}\text { In patients with suspected appendicitis, a tailored individualised approach is } \\
\text { recommended, depending on disease probability, sex and age of the patient. }\end{array}$ & Yes \\
\hline WSES & 2.2 & Imaging should be linked to Risk Stratification such as AIR or Alvarado score & Yes \\
\hline WSES & 2.4 & $\begin{array}{l}\text { Intermediate risk classification identifies patients likely to benefit from observation } \\
\text { and systematic diagnostic imaging. }\end{array}$ & Yes \\
\hline EAES & Preop R2 & $\begin{array}{l}\text { We recommend that ultrasound should be performed as a first-level diagnostic } \\
\text { imaging although it has lower diagnostic value in case radiological confirmation is } \\
\text { desirable. }\end{array}$ & Yes \\
\hline WSES & 2.6 & $\begin{array}{l}\text { US standard reporting templates for ultrasound and US three-step sequential } \\
\text { positioning may enhance over accuracy. }\end{array}$ & \\
\hline EAES & Preop R5 & $\begin{array}{l}\text { In pregnant patients, radiation should be avoided. In case of diagnostic doubt, we } \\
\text { recommend an MRI in these specific patients. }\end{array}$ & \\
\hline WSES & 2.7 & $\begin{array}{l}\mathrm{MRI} \text { is recommended in pregnant patients with suspected appendicitis, if this } \\
\text { resource is available }\end{array}$ & \\
\hline EAES & Preop R6 & $\begin{array}{l}\text { In children radiation should be avoided. In case of diagnostic doubt, we recommend } \\
\text { an MRI in these specific patients. }\end{array}$ & Yes \\
\hline
\end{tabular}

(3) Non-operative treatment for uncomplicated appendicitis

\begin{tabular}{lll} 
WSES & 3.1 & $\begin{array}{l}\text { Antibiotic therapy can be successful in selected patients with uncomplicated } \\
\text { appendicitis who wish to avoid surgery and accept the risk up to } 38 \% \text { recurrence. }\end{array}$ \\
\hline EAES & Preop R7 & $\begin{array}{l}\text { Non-operative treatment (with antibiotics) of uncomplicated appendicitis in adults is } \\
\text { not suggested as high-quality evidence of superiority is still lacking. }\end{array}$ \\
WSES & 3.2 & $\begin{array}{l}\text { Current evidence supports initial intravenous antibiotics with subsequent conversion } \\
\text { to oral antibiotics. }\end{array}$ \\
WSES & 3.3 & $\begin{array}{l}\text { In patients with normal investigations and symptoms unlikely to be appendicitis but } \\
\text { which do not settle: } 1 \text { ) cross-sectional imaging is recommended before surgery; } \\
\text { laparoscopy is the surgical approach of choice and } 3 \text { ) there is inadequate evidence } \\
\text { to recommend a routine approach at present }\end{array}$
\end{tabular}

(4) Timing of appendectomy and in-hospital delay

$\begin{array}{lll}\text { WSES } & 4.1 & \begin{array}{l}\text { Short, in-hospital surgical delay up to 12/24 hours is safe in uncomplicated acute } \\ \text { appendicitis and does not increase complications and/or perforation rate. }\end{array} \\ \text { WSES } & 4.2 & \begin{array}{l}\text { Surgery for uncomplicated appendicitis can be planned for next available list } \\ \text { minimising delay wherever possible (patient comfort, etc). }\end{array}\end{array}$


Table 1 Continued

\begin{tabular}{|c|c|c|c|}
\hline Society & $\begin{array}{l}\text { Statement } \\
\text { number }\end{array}$ & Guidance statement & $\begin{array}{l}\text { Captured } \\
\text { within the RIFT } \\
\text { Study }\end{array}$ \\
\hline EAES & $\begin{array}{l}\text { Operative } \\
\text { R1 }\end{array}$ & We recommend that surgery is performed as soon as feasible after diagnosis. & Yes \\
\hline
\end{tabular}

(5) Surgical treatment

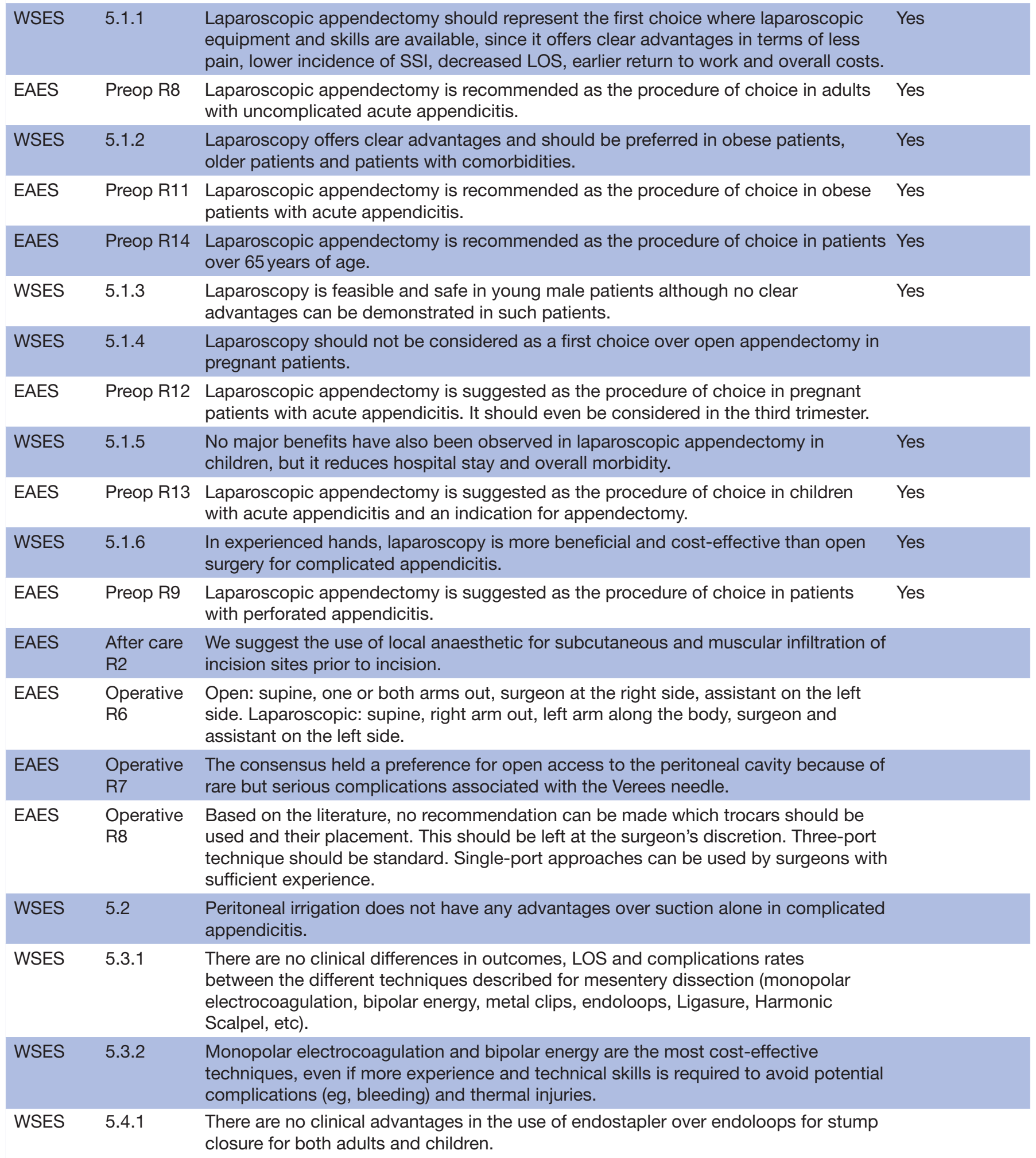


Table 1 Continued

\begin{tabular}{|c|c|c|c|}
\hline Society & $\begin{array}{l}\text { Statement } \\
\text { number }\end{array}$ & Guidance statement & $\begin{array}{l}\text { Captured } \\
\text { within the RIFT } \\
\text { Study }\end{array}$ \\
\hline EAES & $\begin{array}{l}\text { Operative } \\
\text { R10 }\end{array}$ & $\begin{array}{l}\text { The use of stapler or suturing is recommended over clips or endoloops when the } \\
\text { appendix base is inflamed, necrotic or perforated. The use of alternative measures to } \\
\text { secure the appendiceal stump in this case may be insufficient. }\end{array}$ & \\
\hline EAES & $\begin{array}{l}\text { After care } \\
\text { R4 }\end{array}$ & $\begin{array}{l}\text { To prevent stump appendicitis, it is suggested that the appendiceal stump should } \\
\text { be no longer than } 0.5 \mathrm{~cm} \text {. Timely diagnosis allows laparoscopic stump resection. } \\
\text { Delayed diagnosis may require extended bowel resection. }\end{array}$ & \\
\hline WSES & 5.4 .2 & $\begin{array}{l}\text { Endoloops might be preferred for lowering the costs when appropriate skills/learning } \\
\text { curve are available. }\end{array}$ & \\
\hline WSES & 5.4 .3 & $\begin{array}{l}\text { There are no advantages of stump inversion over simple ligation, either in open or } \\
\text { laparoscopic surgery. }\end{array}$ & \\
\hline WSES & 5.5 .1 & Drains are not recommended in complicated appendicitis in paediatric patients. & \\
\hline EAES & $\begin{array}{l}\text { Operative } \\
\text { R5 }\end{array}$ & $\begin{array}{l}\text { It is suggested that there is no indication for routine postoperative catheter } \\
\text { placement in children or adults. }\end{array}$ & \\
\hline WSES & 5.5 .2 & $\begin{array}{l}\text { In adult patients, drain after appendectomy for perforated appendicitis and abscess/ } \\
\text { peritonitis should be used with judicious caution, given the absence of good } \\
\text { evidence from the literature. Drains did not prove any efficacy in preventing intra- } \\
\text { abdominal abscess and seem to be associated with delayed hospital } \\
\text { discharge. }\end{array}$ & \\
\hline EAES & $\begin{array}{l}\text { Operative } \\
\text { R12 }\end{array}$ & $\begin{array}{l}\text { In general, meticulous suction of intraperitoneal fluid or collections is suggested; the } \\
\text { philosophy should be: 'leave no pus behind'. Routine use of drains in appendectomy } \\
\text { is not recommended. }\end{array}$ & \\
\hline EAES & $\begin{array}{l}\text { After care } \\
\text { R3 }\end{array}$ & $\begin{array}{l}\text { There is no reason to restrict the postoperative diet after an uncomplicated } \\
\text { appendectomy. }\end{array}$ & \\
\hline \multicolumn{4}{|c|}{ (6) Scoring systems for intraoperative grading of appendicitis and their clinical usefulness } \\
\hline WSES & 6.1 & $\begin{array}{l}\text { The incidence of unexpected findings in appendectomy specimens is low but the } \\
\text { intraoperative diagnosis alone is insufficient for identifying unexpected disease. From } \\
\text { the current available evidence, routine histopathology is necessary. }\end{array}$ & Yes \\
\hline EAES & $\begin{array}{l}\text { After care } \\
\text { R1 }\end{array}$ & $\begin{array}{l}\text { It is recommended to send all appendices to the pathology department routinely and } \\
\text { the operated will review the results. }\end{array}$ & Yes \\
\hline EAES & $\begin{array}{l}\text { Operative } \\
\text { R15 }\end{array}$ & $\begin{array}{l}\text { It is suggested that definitive treatment of a suspected malignancy will depend } \\
\text { on final histological and staging information after initial treatment of the operative } \\
\text { findings and may require further surgery or adjunct treatment. }\end{array}$ & \\
\hline WSES & 6.2 & $\begin{array}{l}\text { There is a lack of validated system for histological classification of acute appendicitis } \\
\text { and controversies exist on this topic. }\end{array}$ & \\
\hline WSES & 6.3 & $\begin{array}{l}\text { Surgeon's macroscopic judgement of early grades of acute appendicitis is } \\
\text { inaccurate. }\end{array}$ & Yes \\
\hline WSES & 6.4 & $\begin{array}{l}\text { If the appendix looks 'normal' during surgery and no other disease is found in } \\
\text { symptomatic patient, we recommend removal in any case. }\end{array}$ & Yes \\
\hline
\end{tabular}


Table 1 Continued

\begin{tabular}{|c|c|c|c|}
\hline Society & $\begin{array}{l}\text { Statement } \\
\text { number }\end{array}$ & Guidance statement & $\begin{array}{l}\text { Captured } \\
\text { within the RIFT } \\
\text { Study }\end{array}$ \\
\hline EAES & $\begin{array}{l}\text { Operative } \\
\text { R9 }\end{array}$ & $\begin{array}{l}\text { It is suggested to remove the 'normal' appearing appendix when operating for } \\
\text { suspected appendicitis when no other pathology is identified. }\end{array}$ & Yes \\
\hline WSES & 6.5 & $\begin{array}{l}\text { We recommend adoption of a grading system for acute appendicitis based } \\
\text { on clinical, imaging and operative findings, which can allow identification of } \\
\text { homogeneous groups of patients, determining optimal grade disease management } \\
\text { and comparing therapeutic modalities }\end{array}$ & \\
\hline \multicolumn{4}{|c|}{ (7) Non-surgical treatment for complicated appendicitis: abscess or phlegmon } \\
\hline WSES & 7.1 & $\begin{array}{l}\text { Percutaneous drainage of a periappendiceal abscess, if accessible, is an appropriate } \\
\text { treatment in addition to antibiotics for complicated appendicitis. }\end{array}$ & Yes \\
\hline WSES & 7.2 & $\begin{array}{l}\text { Non-operative management is a reasonable first-line treatment for appendicitis with } \\
\text { phlegmon or abscess. }\end{array}$ & Yes \\
\hline WSES & 7.3 & $\begin{array}{l}\text { Operative management of acute appendicitis with phlegmon or abscess is a safe } \\
\text { alternative to non-operative management in experienced hands. }\end{array}$ & Yes \\
\hline EAES & $\begin{array}{l}\text { Operative } \\
\text { R14 }\end{array}$ & $\begin{array}{l}\text { It is recommended to treat an inflammatory mass conservatively. We recommend } \\
\text { that when encountered during laparoscopy, refrain from appendectomy. During } \\
\text { follow-up: additional imaging is advised. Data are lacking on the benefits of interval } \\
\text { appendectomy. }\end{array}$ & \\
\hline WSES & 7.4 & Interval appendectomy is not routinely recommended both in adults and children. & Yes \\
\hline WSES & 7.5 & Interval appendectomy is recommended for those patients with recurrent symptoms. & Yes \\
\hline
\end{tabular}

(8) Preoperative and postoperative antibiotics

\begin{tabular}{|c|c|c|}
\hline WSES & 8.1 & $\begin{array}{l}\text { In patients with acute appendicitis, preoperative broad-spectrum antibiotics are } \\
\text { always recommended. }\end{array}$ \\
\hline EAES & $\begin{array}{l}\text { Operative } \\
\text { R2 }\end{array}$ & Prophylactic antibiotics are recommended in appendectomy in adults. \\
\hline EAES & $\begin{array}{l}\text { Operative } \\
\text { R3 }\end{array}$ & Prophylactic antibiotics are recommended in appendectomy in children. \\
\hline WSES & 8.2 & $\begin{array}{l}\text { For patients with uncomplicated appendicitis, postoperative antibiotics are not } \\
\text { recommended. }\end{array}$ \\
\hline EAES & $\begin{array}{l}\text { After care } \\
\text { S1 }\end{array}$ & Evidence for duration of administration of postoperative antibiotics is lacking. \\
\hline EAES & $\begin{array}{l}\text { After care } \\
\text { S2 }\end{array}$ & $\begin{array}{l}\text { There is no evidence of routine use of postoperative antibiotics in uncomplicated } \\
\text { appendicitis. }\end{array}$ \\
\hline EAES & $\begin{array}{l}\text { After care } \\
\text { R6 }\end{array}$ & In complicated appendicitis, postoperative antibiotics are recommended. \\
\hline
\end{tabular}

Those statements captured within the RIFT study's data collection have been highlighted. The EAES guidance is split into statements (S) and recommendations $(R)$ under three sections; preoperative care, operative managements and after care. The WSES guidance is numbered and listed under the sections described in the table.

EAES, European Association of Endoscopic Surgery's guidance; LOS, length of stay; Preop, preoperative; RIFT, Right Iliac Fossa Pain Treatment; SSI, surgical site infections; WSES, World Society of Emergency Surgery. 


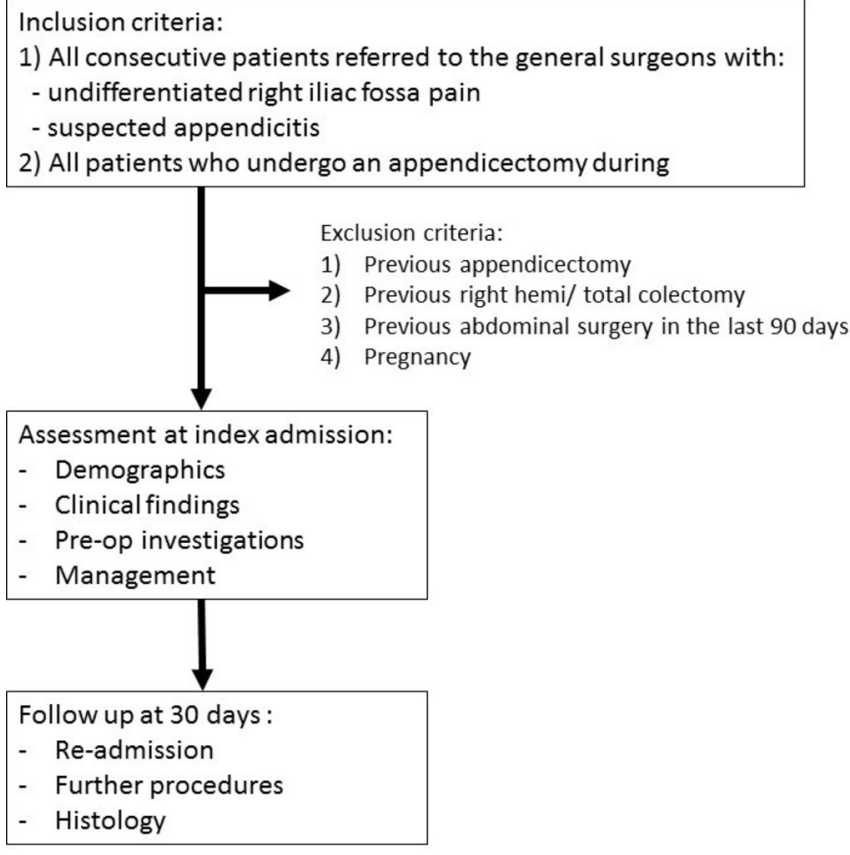

Figure 1 Study flowchart.

laparoscopy rates across participating centres and countries and (2) predictive value of AIR and Alvarado risk scores. Sensitivity, specificity, positive predictive value and negative predictive value will be calculated for clinical risk scores. A panelled multilevel, multivariate, binary logistic regression model, including centre as a random effect, will be used to assess the association of clinical risk scores with negative appendicectomy. The model fit will be tested with area under the curve analysis, using Somer's test to derive a C-statistic.

\section{Ethics}

In the UK the online National Research Ethics Service decision tool (http://www.hra-decisiontools.org.uk) confirmed that RIFT does not require research ethics approval in the UK. The RIFT study will be registered as a clinical audit in each participating UK centre. National leads in other countries will oversee appropriate registration and study approval, which may include completing full ethical review. Local investigators will be responsible for ensuring local approvals are in place and will be required to demonstrate this to gain access to the online data collection tool.

\section{Reporting and dissemination}

A consultant surgeon will facilitate presentation of local study results at a governance meeting at each participating centre. Peer-reviewed publications will be published under corporate authorship including 'RIFT Study Group' and 'West Midlands Research Collaborative'.

\section{DISCUSSION}

The RIFT study will be a large, multicentre, international, prospective observational study of undifferentiated patients presenting with RIF pain and suspected appendicitis. By using a protocol driven, preplanned data collection tool and analysis plan, this study will ensure high data quality while minimising the burden on participating centres.

The 2012 national appendicectomy audit found a significant variation in management of appendicitis across the UK. ${ }^{7}$ In light of recent guidelines stipulating that appendicectomy in adults should be performed laparoscopically unless contraindicated, ${ }^{9}{ }^{10}$ the RIFT study offers the opportunity to examine health system-level quality improvement in the delivery of laparoscopic appendicectomy 5 years on from the 2012 study. By mapping real-life patient pathways for investigation and management of RIF pain, RIFT will indicate whether any increased use of modern technologies, including CT scanning and laparoscopy, have been associated with a decrease in the rate of negative appendicectomy.

Validation of the AIR and Alvarado scores in a large international cohort will determine the suitability of using these to stratify patients in to low, medium and high-risk groups for appendicitis, as envisaged by recent guidelines. ${ }^{9}$ If these risk scores are found to have poor prognostic properties, it may be possible to develop and validate a new score based on the RIFT dataset. Risk scores may aid junior clinicians' decision-making and may have a role in avoiding unnecessary operations, reducing the negative appendicectomy rate and improving patient safety. ${ }^{5}$ Furthermore, validated risk scores may be particularly useful in low resource settings with limited access to diagnostic investigations.

The UK National Surgical Research Collaborative's member groups have run trainee-led collaborative studies across $99 \%$ of the UK's surgical units, ${ }^{12}$ delivering large, prospective studies. ${ }^{7}$ However, as trainees complete their training and become consultants, the sustainability of postgraduate trainee research collaboratives will be dependent on engaging new junior trainees each year. Whereas previous studies undertaken by surgical research collaboratives have been targeted at either senior trainees or medical students, RIFT is the first study aimed at junior specialty trainees (recent graduates). A surrogate marker for the success of RIFT will therefore be successful engagement and mentoring of junior trainees in collaborative research.

\section{Limitations}

The RIFT Study Group has made specific efforts to minimise the risk of inherent bias in this observational study. Data will be collected prospectively and patient pathways followed proactively by collaborators, who will often be the frontline clinicians responsible for the patients' care. Unlike most previous studies which have focused specifically on patients who undergo appendicectomy, RIFT will include all patients presenting with RIF pain or suspected appendicitis, to general surgical services. Nonetheless, since these patients will have already been triaged by emergency 


\begin{tabular}{|c|c|c|}
\hline & Data criteria & Options \\
\hline \multicolumn{3}{|c|}{ Centre details } \\
\hline 1(a) & Does your unit care for? & $\begin{array}{l}\text { - Adults only } \\
\text { - Children only } \\
\text { - Adults and children }\end{array}$ \\
\hline 2 & Does your hospital have an on-site gynaecology service? & $\begin{array}{l}\text { - Yes } \\
\text { - No }\end{array}$ \\
\hline 3 & $\begin{array}{l}\text { Does your centre have 'review clinic' slots for patients to return } \\
\text { for further assessment/imaging the following day if a diagnosis is } \\
\text { unclear? }\end{array}$ & $\begin{array}{l}\text { Yes-with ultrasound and clinical review } \\
\text { - Yes - clinical review only } \\
\text { - No }\end{array}$ \\
\hline 4(a) & $\begin{array}{l}\text { How many consultants will be 'on call' during the 2-week study } \\
\text { period? }\end{array}$ & Number $=$ \\
\hline 4(b) & How many consultant general surgeons work at your centre? & Number $=$ \\
\hline 4(c) & $\begin{array}{l}\text { Is there a dedicated registrar based on the surgical assessment } \\
\text { unit to review patients? }\end{array}$ & $\begin{array}{l}\text { Yes-24/7 } \\
\text { Yes-during the day } \\
\text { No-one registrar splits time between theatre } \\
\text { and the surgical assessmment unit }\end{array}$ \\
\hline 5 & At weekends, is ultrasound available? & $\begin{array}{l}\text { - Yes } \\
\text { - No }\end{array}$ \\
\hline 6(a) & At weekends, is CT available? & $\begin{array}{l}\text { Equivalent to weekday service } \\
\text { Reduced service but available for urgent surgical } \\
\text { requests } \\
\text { Not available }\end{array}$ \\
\hline 6(b) & At night, is CT available? & $\begin{array}{l}\text { Equivalent to weekday service } \\
\text { - Reduced service but available for urgent surgical } \\
\text { requests } \\
\text { - Not available }\end{array}$ \\
\hline \multicolumn{3}{|c|}{ Does your centre have an agreed policy for: } \\
\hline 7 & When to use appendicitis risk stratification scores? & $\begin{array}{l}\text { Yes-use of score recommended } \\
\text { Yes-use of score discouraged } \\
\text { - No policy in place }\end{array}$ \\
\hline 8 & $\begin{array}{l}\text { Which patients should have a CT scan prior to appendicectomy? } \\
\text { (eg, diagnosis unclear, age }>50)\end{array}$ & $\begin{array}{l}\text { Yes-please detail } \\
\text { No policy in place }\end{array}$ \\
\hline 9 & $\begin{array}{l}\text { Whether some patients with appendicitis may be managed non- } \\
\text { operatively? }\end{array}$ & $\begin{array}{l}\text { Yes-conservative management recommended } \\
\text { for some patients; please detail } \\
\text { Yes - policy discourages conservative } \\
\text { management } \\
\text { - No policy in place }\end{array}$ \\
\hline 10 & $\begin{array}{l}\text { Whether laparoscopic or open appendicectomy should be } \\
\text { routinely performed? }\end{array}$ & $\begin{array}{l}\text { Yes-open surgery recommended } \\
\text { Yes-laparoscopic surgery recommended } \\
\text { - No policy in place }\end{array}$ \\
\hline 11 & $\begin{array}{l}\text { Whether a macroscopically normal looking appendix should be } \\
\text { removed or left in situ? }\end{array}$ & $\begin{array}{l}\text { Yes-removal recommended } \\
\text { Yes-recommend it be left in situ } \\
\text { - No-no policy in place }\end{array}$ \\
\hline
\end{tabular}

department or general practice doctors, this is likely to be a selected group who are more likely to have appendicitis than patients with truly undifferentiated presentations.

Given the large volume of patients presenting with RIF pain and the short inpatient stays that most patients have reliably identifying all eligible patients will be more challenging than in previous studies run by trainee collaboratives. However, preplanned validation by an independent investigator will ensure that case ascertainment rates are monitored. This will also mitigate any risk of reporting bias from clinicians declining to submit details of patients that have been misdiagnosed at their centre. 
*Due to the pragmatic 'snap-shot' nature of this study, carried out by practising clinicians, there is a limit to the depth and breadth of data points included. For instance, the study will not collect the length and nature of perioperative antibiotic treatment (table 1). Furthermore, follow-up is limited to 30 days after the index hospital admission. It is possible that a proportion of patients initially discharged having not undergone appendicectomy may subsequently be readmitted and undergo surgery either at other hospitals or beyond the 30-day follow-up.

In summary, the RIFT study is a protocol-driven, international, multicentre prospective observational study using a 'snap-shot' methodology, in line with the UK surgical research collaborative model. The study aims to describe the current variation in investigation and management of right iliac fossa pain in several European countries, aligned to contemporaneous specialty guidelines.

\section{Twitter @WMRC_UK}

Collaborators WMRC Collaborating members are listed in the online supplementary appendix 1 .

Contributors Conception and writing of protocol: Jacob H Matthews, Gabriella L Morley, Shivam Bhanderi, Sarus Jain, Imran Mohamed, Thuvarahan Amuthalingam, Robert Tyler, James C Glasbey, Richard Wilkin, Dmitri Nepogodiev, Aneel Bhangu. Participation in collaborator meeting, development of study concept and editing of protocol: Jacob H Matthews, Gabriella L Morley, Shivam Bhanderi, Sarus Jain, Imran Mohamed, Thuvarahan Amuthalingam, Robert Tyler, James C Glasbey, Ewen Griffiths, Thomas Pinkney, Oliver Gee, Dion Morton, Francesco Pata, Gianluca Pellino, Valeria Farina, Laura Gavagna, Pietro Maria Naccari, Sandro Pasquali, Bruno Sensi, Alessandro Sgrò, Andrea Simioni, Ruth Blanco-Colino, Matteo Frasson, Antonio Sampaio Soares, Natalie Blencowe, Will Bolton, Stephen Chapman, Catherine Bradshaw, Grant Harris, James B Haddow, Kapil Sahnan, John Mason, Scott McCain, David Milgrom, Saleem Noor Mohamed, James O'Brien, Jack Pearce Mohammed Rabie, Gaël R Nana, Panchali Sarmah, Nigel Jamieson, Richard Wilkin, Dmitri Nepogodiev, Aneel Bhangu. Guarantor: Aneel Bhangu. All authors read and approved the final manuscript.

Competing interests None declared.

Ethics approval In the United Kingdom this observational study does not require research ethics approval. The study will be registered as a clinical audit in each participating UK centre. National leads in the other participating countries will ensure appropriate registration and study approval in compliance with local regulations;, this may require full ethical review in some jurisdictions. Local investigators are responsible for ensuring local approvals are in place.

Provenance and peer review Not commissioned; externally peer reviewed.
Open Access This is an Open Access article distributed in accordance with the Creative Commons Attribution Non Commercial (CC BY-NC 4.0) license, which permits others to distribute, remix, adapt, build upon this work non-commercially, and license their derivative works on different terms, provided the original work is properly cited and the use is non-commercial. See: http://creativecommons.org/ licenses/by-nc/4.0/

(C) Article author(s) (or their employer(s) unless otherwise stated in the text of the article) 2018. All rights reserved. No commercial use is permitted unless otherwise expressly granted.

\section{REFERENCES}

1. Royal College of Surgeons and Association of Surgeons of Great Britain and Ireland. Commissioning guide 2014: emergency general surgery (acute abdominal pain). London, 2014. https://www.rcseng. ac.uk/-/media/./commissioning-guide-egs-published-v3.pdf (accessed on 1 Jan 2017).

2. Bhangu A, Søreide K, Di Saverio S, et al. Acute appendicitis: modern understanding of pathogenesis, diagnosis, and management. Lancet 2015;386:1278-87.

3. Andersson M, Andersson RE. The appendicitis inflammatory response score: a tool for the diagnosis of acute appendicitis that outperforms the Alvarado score. World J Surg 2008;32:1843-9.

4. Alvarado A. A practical score for the early diagnosis of acute appendicitis. Ann Emerg Med 1986;15:557-64.

5. Kularatna M, Lauti M, Haran C, et al. Clinical Prediction Rules for Appendicitis in Adults: Which Is Best? World J Surg 2017;41:1769-81.

6. Bhangu A, short Sof; United Kingdom National Surgical Research Collaborative. Safety of short, in-hospital delays before surgery for acute appendicitis: multicentre cohort study, systematic review, and meta-analysis. Ann Surg 2014;259:894-903.

7. National Surgical Research Collaborative. Multicentre observational study of performance variation in provision and outcome of emergency appendicectomy. Br J Surg 2013;100:1240-52.

8. Baird DLH, Simillis C, Kontovounisios C, et al. Acute appendicitis. BMJ 2017;357:j1703.

9. Di Saverio S, Birindelli A, Kelly MD, et al. WSES Jerusalem guidelines for diagnosis and treatment of acute appendicitis. World J Emerg Surg 2016;11:34.

10. Gorter RR, Eker HH, Gorter-Stam MA, et al. Diagnosis and management of acute appendicitis. EAES consensus development conference 2015. Surg Endosc 2016;30:4668-90.

11. Bhangu A, Kolias AG, Pinkney T, et al. Surgical research collaboratives in the UK. Lancet 2013;382:1091-2.

12. Nepogodiev D, Chapman SJ, Kolias AG, et al. On behalf of the National Surgical Research Collaborative). The impact of research collaboratives in the UK. Lancet Gastroenterology \& Hepatology 2017;2:247-8.

13. Khatri C, Chapman SJ, Glasbey J, et al. Social media and internet driven study recruitment: evaluating a new model for promoting collaborator engagement and participation. PLOS One 2015;10:e0118899.

14. von Elm E, Altman DG, Egger M, et al. The Strengthening the Reporting of Observational Studies in Epidemiology (STROBE) Statement: guidelines for reporting observational studies. Int $J$ Surg 2014;12:1495-9. 